\title{
Multi-site binding of drugs and natural products in an entropically- favorable, heteroleptic receptor
}

\author{
Felix J. Rizzuto, John P. Carpenter, Jonathan R. Nitschke* \\ University of Cambridge, Department of Chemistry, Cambridge UK, CB2 1EW \\ *Correspondence to: jrn34@cam.ac.uk
}

\begin{abstract}
The cavities of artificial receptors are defined by how their components fit together. The encapsulation of specific molecules can thus be engineered by considering geometric principles; however, intermolecular interactions and steric fit scale with receptor size, such that the ability to bind multiple guests from a specific class of compounds remains a current challenge. By employing metal-organic self-assembly, we have prepared a triangular prism from two different ligands that is capable of binding more than twenty different natural products, drugs and steroid derivatives within its prolate cavity. Encapsulation inflates the host, enhancing its ability to bind other guests in peripheral pockets, and thus enabling our system to bind combinations of different drug and natural product cargoes in different locations simultaneously. This new mode of entropically-favorable self-assembly thus enables central encapsulation to amplify guest binding events around the periphery of an artificial receptor.
\end{abstract}

\section{Introduction}

Natural products are often information-rich, with asymmetric structures that contain multiple stereocenters. These properties render them challenging to encapsulate with high affinity within synthetic self-assembled receptors, ${ }^{1-5}$ which tend to have cavities that approximate spheres. ${ }^{6-16}$ Self-assembly pathways that generate receptors with anisotropic void spaces consequently diversify the range of guests that may be bound. ${ }^{17-19}$ Successful strategies to generate asymmetrical receptors include the use of twofold-symmetric building blocks to form lantern-shaped hosts ${ }^{20-24}$ and multi-step organic synthesis to produce tailored binding pockets. ${ }^{25-29}$ However, larger assemblies prepared using these methods tend to be porous, limiting the density of favorable intermolecular interactions between host and guest, thus hindering high-affinity binding. 
Asymmetrical binding environments can also be created through heteroleptic assembly, wherein multiple different building blocks combine to generate a single entity. ${ }^{17,30-39}$ The bringing together of multiple components into one specific configuration, from among other possibilities, usually incurs an entropic penalty. The selective synthesis of heteroleptic structures is thus often designed to be enthalpically favorable, as strain within homoleptic derivatives is avoided upon formation of a mixed-ligand system. ${ }^{40-43}$ Understanding the factors leading to heteroleptic assembly would enable artificial receptors to be designed for the encapsulation of low-symmetry and asymmetric guests that cannot be bound by their homoleptic analogs.

Here we describe the factors leading to the selective formation of a new and useful triangularprismatic host framework, and quantify its remarkable ability to selectively bind a collection of pharmaceutically-relevant molecules. Entropy, as opposed to enthalpy, drives the selective synthesis of this heteroleptic triangular prism over the homoleptic cubes and tetrahedra usually observed. Whereas the central binding sites of both homoleptic species are roughly spherical, those of the triangular prisms are prolate. This decreased symmetry promoted the binding of a collection of complex natural products - steroids, opiates, alkaloids and other drugs bound within the prisms, but not within the cubes or tetrahedra. Upon binding one guest internally, the prism inflated to express a set of secondary, peripheral binding sites. The malleable nature of the structure induced complex binding interactions involving collections of guests, including cooperative binding events and guest aggregation around the cage, underscoring the utility of our system to generate diverse host-guest dynamics from simple building blocks.

\section{Results and Discussion}

Entropically-favorable self-assembly. Triangular prism 1 was synthesized from $\mathrm{Ni}^{\mathrm{II}}$-porphyrin A (3 equiv), triamine $\mathbf{B}$ ( 2 equiv), 2-formylpyridine (18 equiv) and $\mathrm{Zn}^{\mathrm{II}}$ ( 6 equiv) in $\mathrm{CH}_{3} \mathrm{CN}$ (Fig. 1a, SI Section 2). The ${ }^{1} \mathrm{H}$ NMR spectrum of 1 displayed twofold desymmetrization of the porphyrin unit with maintenance of threefold rotational symmetry of the triamine unit, consistent with the $D_{3}$ point symmetry of a triangular prism. Mass spectrometry revealed the $\mathrm{Zn}^{\mathrm{II}}{ }_{6} \mathbf{L}^{\mathbf{A}_{3}} \mathbf{L}^{\mathbf{B}_{2}}$ composition of 1 and single-crystal X-ray diffraction (Fig. 1c) confirmed its face-capped triangular prismatic structure. Both the all- $\Delta$ and all- $\Lambda$ enantiomers of 1 present in the crystal. $\mathrm{Zn}^{\mathrm{II}}-\mathrm{Zn}^{\mathrm{II}}$ distances were observed to be slightly shorter around the parallel triangular faces $(14.2-14.7 \AA)$ than they were 
between them $(15.2-15.4 \AA)$ within 1 . This stands in contrast to the crystal structures of homoleptic products: $\mathrm{Zn}{ }^{\mathrm{II}}-\mathrm{Zn}^{\mathrm{II}}$ distances were $15.7 \AA$ in tetrahedron $\mathbf{2}$, and $14.8-15.2$ in cube $\mathbf{3}$.

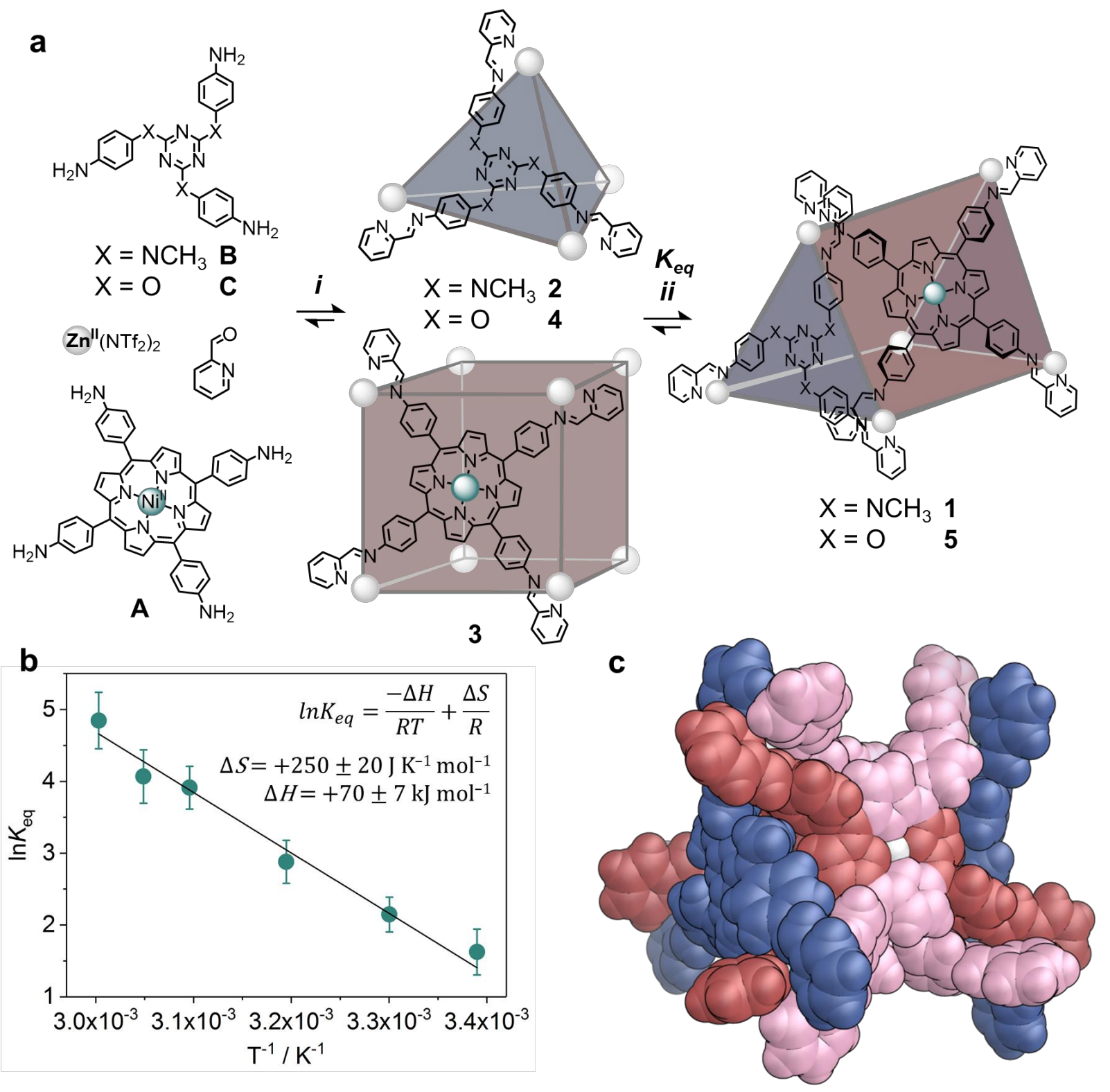

Figure 1. Entropy as a driving force for generating heteroleptic 1. a, Self-assembly of $\mathbf{1}$ from subcomponents $\mathbf{A}, \mathbf{B}$, 2-formylpyridine and $\mathrm{Zn}^{\mathrm{II}}$ templates, or from the conproportionation of homoleptic cages 2 and 3. Conditions: $\boldsymbol{i}$, $\mathrm{CH}_{3} \mathrm{CN}, 50{ }^{\circ} \mathrm{C}$; ii, $\mathrm{CH}_{3} \mathrm{CN}, 70{ }^{\circ} \mathrm{C}$ to generate 1 ; $\mathrm{CoC}_{4} \mathrm{~B}_{18} \mathrm{H}_{22}{ }^{-}, 50{ }^{\circ} \mathrm{C}$ to generate 5. b, van 't Hoff analysis of the equilibrium of aii. c, X-ray crystal structure of $\mathbf{1}$, with each set of unique proton environments highlighted in a different color, showing the $D_{3}$ point symmetry of the assembly. 
In each others' absence, subcomponent $\mathbf{B}$ produced tetrahedron $\mathbf{2}$ and subcomponent $\mathbf{C}$ produced cube 3 (Fig. 1a). Heating A, B and 2-formylpyridine together with $\mathrm{Zn}^{\mathrm{II}}$ at $50^{\circ} \mathrm{C}$ produced a ${ }^{1} \mathrm{H}$ NMR spectrum wherein all three products (1, 2, and $\left.\mathbf{3}\right)$ were observed (SI Section 3), whereas 1 was isolated as the exclusive product at $70^{\circ} \mathrm{C}$. A van 't Hoff analysis of the equilibrium between the heteroleptic and homoleptic structures indicated that the generation of the triangular prism was an enthalpically-disfavored process; entropy drives its formation, such that $\Delta H=+70 \pm 8 \mathrm{~kJ} \mathrm{~mol}^{-}$ ${ }^{1}$ and $\Delta S=+250 \pm 20 \mathrm{~J} \mathrm{~K}^{-1} \mathrm{~mol}^{-1}$ for the equilibrium $\mathbf{2}+\mathbf{3} \rightleftharpoons 2 \cdot \mathbf{1}$ (Fig. 1b).

We attribute the positive entropy change associated with the formation of $\mathbf{1}$ to two factors. First, we infer 1 to possess a greater number of conformational microstates than the combination of $\mathbf{2}$ and 3. The crystal structure of $\mathbf{1}$ and its host-guest complexes (discussed below) revealed that each of the $\mathrm{Ni}^{\mathrm{II}}$ porphyrins in $\mathbf{1}$ existed in one of two saddled conformations, whereas the $\mathrm{Ni}^{\mathrm{II}}$ porphyrin units in $\mathbf{3}$ are planar. Because the porphyrin cores of $\mathbf{1}$ may thus exist in one of two microstates, whereas 3 lacks these degrees of freedom, the formation of $\mathbf{1}$ will be favored entropically by $+35 \mathrm{~J} \mathrm{~K}^{-1} \mathrm{~mol}^{-1}$ (SI Section 3.1).

Second, 1 entraps fewer solvent molecules than the corresponding mixture of $\mathbf{2}$ and $\mathbf{3}$. A comparison of void volumes between the homo- vs. heteroleptic products (SI Section 4) revealed the combined cavity space of $\mathbf{2}$ and 3 to be larger than two equivalents of $\mathbf{1}$ (310-740 $\AA^{3}$ greater, depending on the conformation of the porphyrins in 1). This decrease in volume means that two equivalents of 1 encapsulate 6-14 fewer acetonitrile molecules, as compared to one equivalent of both 2 and 3 (SI Section 3.2).

Entropy changes resulting from structural transformations are rarely quantified in cage systems; fewer still are investigated in organic solvents. ${ }^{44}$ Entropy changes associated with guest encapsulation are better understood - the expulsion of solvent from the cavity of a cage provides an entropic driving force for guest binding. ${ }^{45,46}$ Noting that the volume of one equivalent of 1 (415$\left.630 \AA^{3}\right)$ is comparable to the volume change associated with the equilibrium $\mathbf{2}+\mathbf{3} \rightleftharpoons 2 \cdot \mathbf{1}(310$ $740 \AA^{3}$ ), we quantified the entropy change associated with guest binding within 1, proposing that this value may be used to estimate the entropy change upon the formation of heteroleptic products from homoleptic ones.

The encapsulation of cobalticarborane within 1 was observed to lead to a system entropy change of $+206 \pm 9 \mathrm{~J} \mathrm{~K}^{-1} \mathrm{~mol}^{-1}$, which we attribute to the liberation of $\mathrm{CH}_{3} \mathrm{CN}$ from the cavity (Fig. S15). This value is in line with analogous investigations on cages with similarly-sized cavities 
in $\mathrm{MeCN},{ }^{47}$ and may be used to approximate the entropy change associated with solvent expulsion in forming heteroleptic $\mathbf{1}$ from homoleptic $\mathbf{2}$ and $\mathbf{3}$.

When taken together, the microstates and solvent-liberation contributions thus predict an entropic driving force for the formation of 1 of $c a .+240 \mathrm{~J} \mathrm{~K}^{-1} \mathrm{~mol}^{-1}$, which is within the uncertainty of our experimental value. Although the number of components and bonds remain the same on both sides of the equilibrium, conformational freedom and a smaller number of trapped solvent molecules renders heteroleptic $\mathbf{1}$ entropically favorable with respect to homoleptic $\mathbf{2}$ and $\mathbf{3}$, thus providing a new rationale for heteroleptic self-assembly.

A subtle stereochemical difference between trigonal prism $\mathbf{1}$ and tetrahedron $\mathbf{2}$ helps to explain why $\mathbf{2}$ is enthalpically disfavored with respect to $\mathbf{1}$. In the all- $\left(\Lambda-\mathrm{Zn}^{\mathrm{II}}\right)$ configuration of $\mathbf{2}$, the triskelions of its $\mathbf{B}$ residues may be oriented in either a clockwise or an anticlockwise configuration, yielding energetically-distinct diastereomers. However, only the all-clockwise $\Lambda$ $\mathrm{Zn}^{\mathrm{II}}$ configuration (and its $\Delta$ /anticlockwise enantiomer) has been observed for $\mathbf{2}$ (Fig. 2a) and its $\mathrm{Fe}^{\mathrm{II}}$ congener in the solid state ${ }^{48}$, leading us to infer this diastereomeric configuration to be energetically favorable.

In the case of 1 and its host-guest complexes, however, $\Lambda-\mathrm{Zn}^{\mathrm{II}}$ vertices are paired with anticlockwise oriented triskelions (Fig. 2c-f). Because its absence from 2 suggests the $\Lambda /$ anticlockwise configuration to be enthalpically unfavorable, its presence in $\mathbf{1}$ may be inferred to represent a kind of structural compromise, whereby an enthalpic penalty is built in to a structure that is nonetheless thermodynamically favorable owing to the entropic gain described above.

Templates were necessary to favor the formation of triangular prism $\mathbf{5}$, a congener of 1 (SI Section 5). Employing ether-bridged $\mathbf{C}$ in place of amine-bridged $\mathbf{B}$ during the assembly process led initially to the exclusive formation of homoleptic products (i.e., the tetrahedron $\mathbf{4}$ and cube $\mathbf{3}$ ) at $70{ }^{\circ} \mathrm{C}$. When testosterone or sodium cobalticarborate $\left(\mathrm{NaCoC}_{4} \mathrm{~B}_{18} \mathrm{H}_{22}\right)$ was added and the mixture heated to $70{ }^{\circ} \mathrm{C}$ for a further $24 \mathrm{~h}$, triangular prism 5 was obtained in $>90 \%$ yield. The subtle balance between the hetero- and homoleptic products in this system is thus tipped in favor of heteroleptic 5 by an asymmetrical template. 

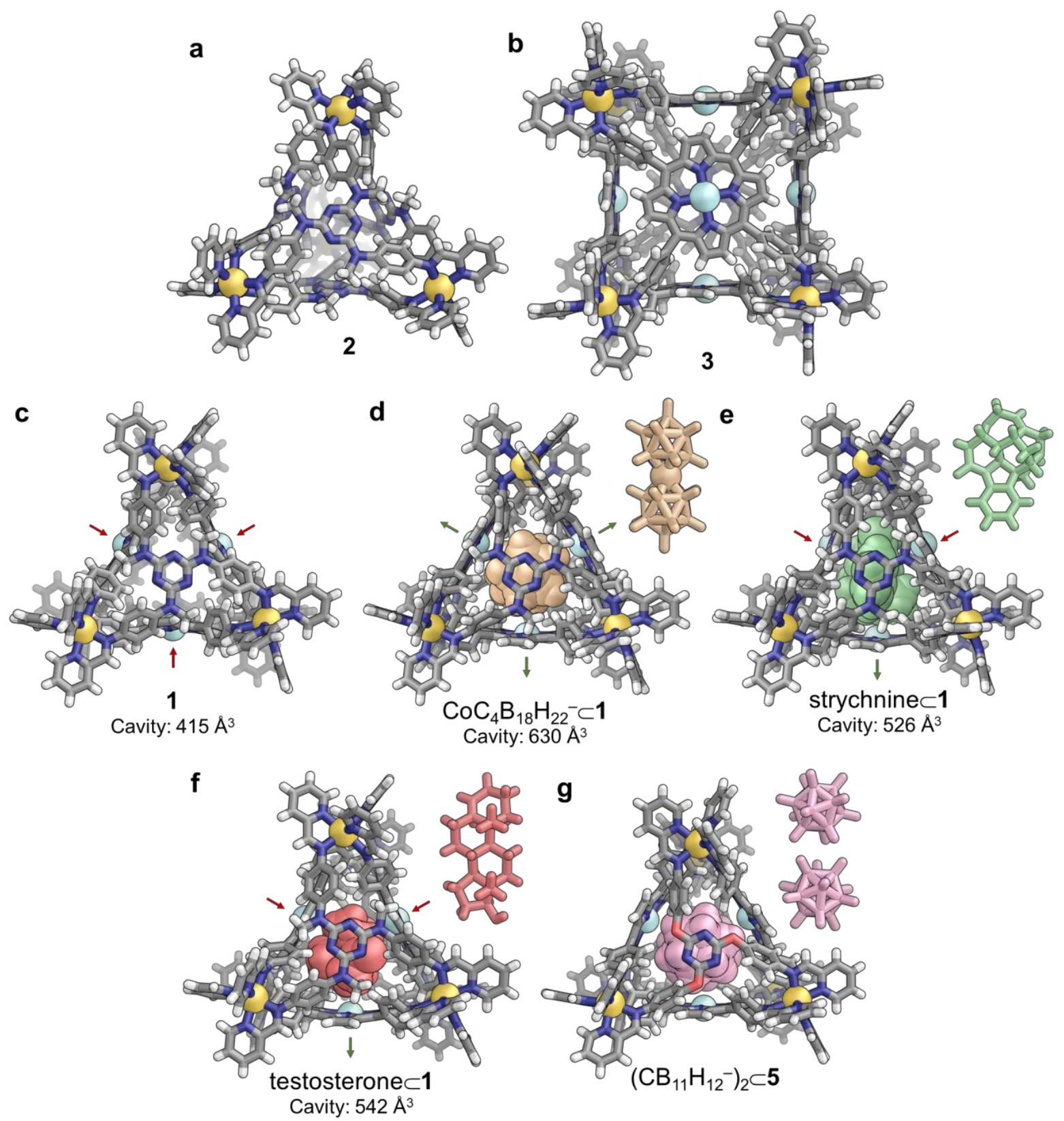

Figure 2. X-ray crystal structures of assemblies and host-guest complexes. Solid-state structures of a, 2; b, 3; c, 1; d, $\mathrm{CoC}_{4} \mathrm{~B}_{18} \mathrm{H}_{22}{ }^{-} \subset \mathbf{1} ; \mathbf{e}$, strychnine $\subset \mathbf{1} ; \mathbf{f}$, testosterone $\subset \mathbf{1} ; \mathbf{g},\left(\mathrm{CB}_{11} \mathrm{H}_{12}{ }^{-}\right)_{2} \subset \mathbf{5}$. All heteroleptic structures are viewed down their $C_{3}$ axes. Red and green arrows indicate concave and convex porphyrins, respectively. Each guest is shown in a different color. For the cages, $\mathrm{Zn}$ - yellow, $\mathrm{Ni}$ - cyan, $\mathrm{C}$ - grey, $\mathrm{N}$ - blue, $\mathrm{O}$ - red, $\mathrm{H}$ - white; solvent, non-binding anions, and disorder are not shown for clarity. 
Host-guest dynamics. Noting its ability to template 5, we investigated the binding of $\mathrm{CoC}_{4} \mathrm{~B}_{18} \mathrm{H}_{22}{ }^{-}$ within 1. Cobalticarborane was observed to bind to $\mathbf{1}$ in slow exchange on the NMR timescale, with $K_{\mathrm{a}}>10^{4} \mathrm{M}^{-1}$. The single-crystal X-ray structure of cobalticarborane bound within 1 (Fig. 2d) indicated that encapsulation led to a bulging outward of the porphyrin subunits, whereas in free $\mathbf{1}$ the porphyrins bulged inward (Fig. 2c). This reconfiguration led to a 52\% increase in the cavity volume of 1 (from 415 to $630 \AA^{3}$ ) following the binding of $\mathrm{CoC}_{4} \mathrm{~B}_{18} \mathrm{H}_{22}$. The distinct conformational microstates of the porphyrin ligands of $\mathbf{1}$ thus adapted in order to optimize encapsulation.

Similar morphology changes were observed in the solid-state structure of $\mathbf{5}$, which housed two $\mathrm{CB}_{11} \mathrm{H}_{12}{ }^{-}$anions (Fig. 2g). These anions bound non-cooperatively within $\mathbf{1}$, as determined by ${ }^{1} \mathrm{H}$ NMR titration. In contrast, two molecules of neutral adamantane bound with positive allosteric cooperativity ${ }^{49}$ within 1 , with a cooperativity parameter of $\alpha={ }_{4} K_{2} / K_{1}=5.8 \pm 0.3$. Guest signals were shifted downfield by $c a$. 5 ppm relative to their free values, with maintenance of $D_{3}$ host symmetry.

Further exploration of the guest-binding abilities of $\mathbf{1}$ revealed the binding of structurally complex natural products, steroids and drugs (Fig. 3). A series of steroids - estrogens, androgens, corticoids, progestogens and synthetic drug analogues - and smaller terpenoids - santonin and totarol - were observed to bind in slow exchange on the NMR timescale. The proton signals of the guest were shifted upfield by up to $7 \mathrm{ppm}$ upon binding to 1 , appearing in the range -1 to $-6 \mathrm{ppm}$ (Fig. 4, SI Section 6.3). For testosterone $\subset 1$, ${ }^{1} \mathrm{H}$ NOE correlations between the phenylene protons of 1 and multiple proton signals of the guest were identified, all consistent with internal binding. A crystal structure of testosterone bound within 1 was also obtained (Fig. 2f). For all host-guest complexes, mass spectra were consistent with the encapsulation of a single guest (Fig. S44). 

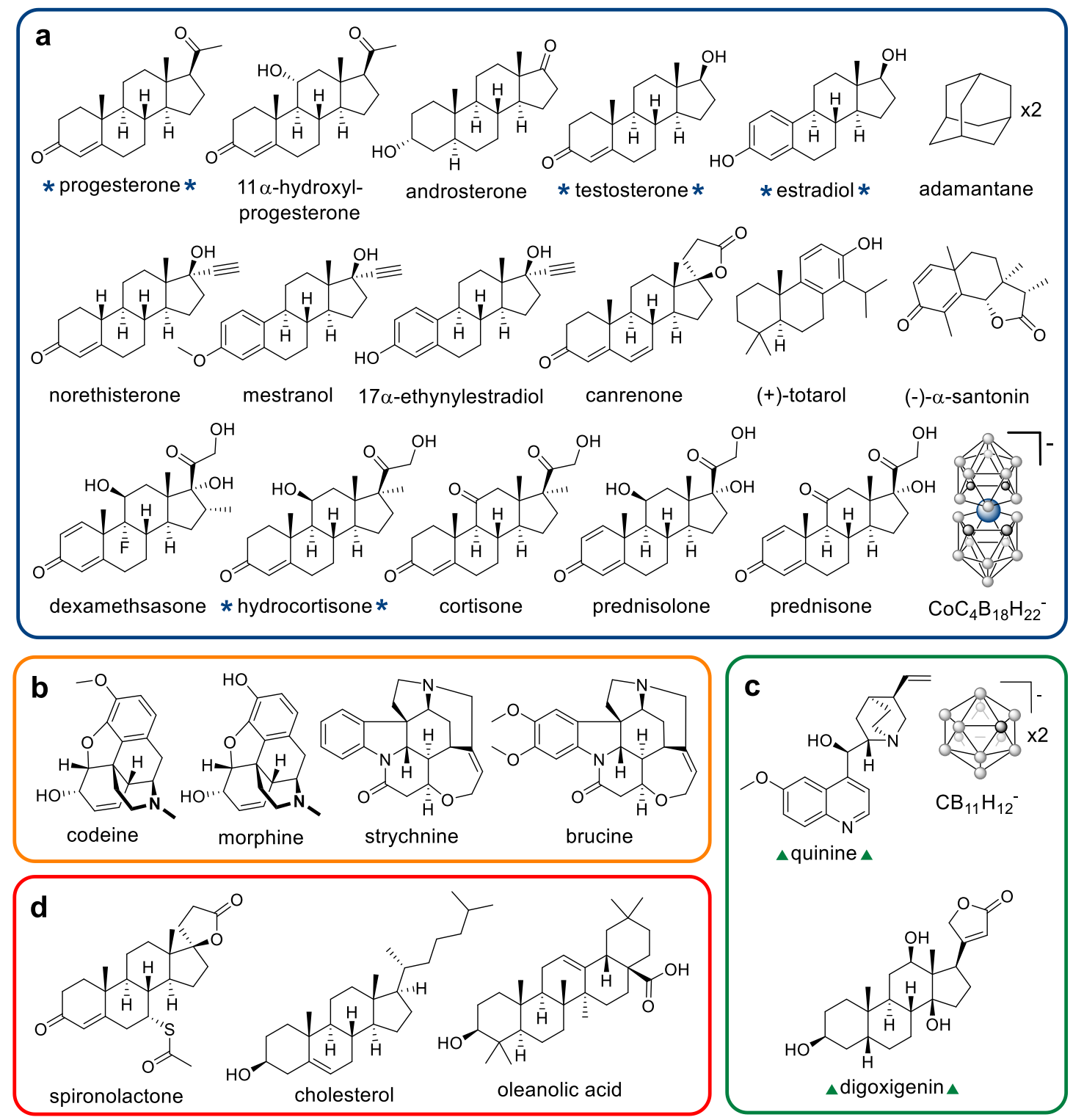

$\Delta$ quinine

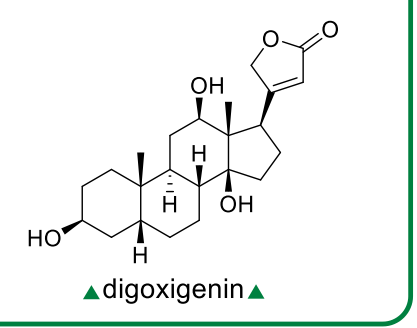

Figure 3. Host-guest chemistry of 1. a, Guests that bound in slow exchange. b, Guests showed significant spectral broadening, suggesting intermediate exchange rates. c, Fast exchange binding guests. d, Molecules that had no observable interaction with $\mathbf{1}$. Guests that displayed both internal and peripheral binding to $\mathbf{1}$ are marked with blue asterisks; those that bound only peripherally are marked with green triangles. 


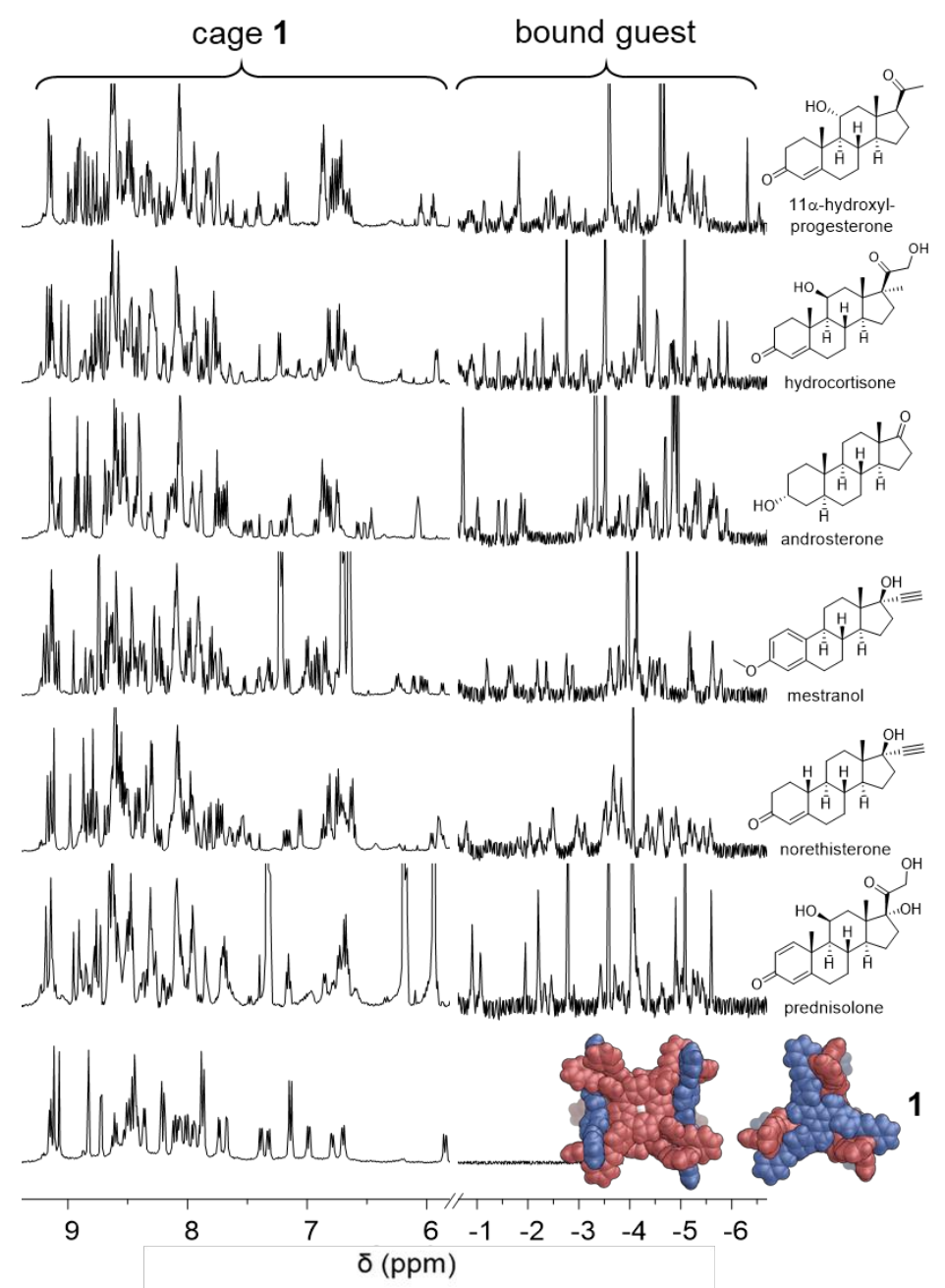

Figure 4. ${ }^{1} \mathrm{H}$ NMR spectra $\left(500 \mathrm{MHz}, 298 \mathrm{~K}, \mathrm{CD}_{3} \mathrm{CN}\right)$ of $\mathbf{1}$ and selected host-guest adducts.

Binding constants for steroid adducts of $\mathbf{1}$ (Table 1) were determined by ${ }^{1} \mathrm{H}$ NMR integration, averaged over three different host:guest ratios. Androgens and progestogens were thus the strongest binding guests, with $K_{\mathrm{a}}>10^{4} \mathrm{M}^{-1}$. Guests with equatorial $\mathrm{OH}$ moieties (hydrocortisone and prednisolone with $11 \alpha-\mathrm{OH}$, and ethynylestradiol, with a 3-OH moiety) bound with intermediate strength, followed by guests with more sterically demanding units at their termini. We discerned no clear correlation between the linearity of a guest and its binding affinity: for instance, prednisone and prednisolone are bent to a similar degree, and are both more bowed than testosterone (which binds more strongly) and cortisone (which binds more weakly). Steroids bearing a secondary alcohol moiety, as opposed to a ketone, at the 11-position of the steroid 
backbone bound an order of magnitude more strongly: hydrocortisone or prednisolone were both much better guests than cortisone or prednisone. A size limitation for binding within $\mathbf{1}$ was also observed: steroids with bulky axial substituents (e.g. spironolactone) or long alkyl chains (e.g. cholesterol) do not fit within 1, leading to no observable binding (Fig. 3d). Canrenone and dexamethasone were the largest guests to show clear evidence of encapsulation, and the diterpenoids totarol and santonin were the smallest guests.

Table 1. Binding constants of steroid and drug guests within 1, in order of binding affinity, determined by ${ }^{1} \mathrm{H}$ NMR titrations $\left(298 \mathrm{~K}, \mathrm{CD}_{3} \mathrm{CN}\right)$.

\begin{tabular}{lc}
\hline Guest & $\boldsymbol{K}_{\mathbf{a}}\left(\times \mathbf{1 0}^{\mathbf{2}} \mathbf{M}^{\mathbf{- 1}}\right)$ \\
\hline Testosterone & $>500^{[\mathrm{a}]}$ \\
Androsterone & $>500^{[\mathrm{a}]}$ \\
Progesterone & $390 \pm 30$ \\
Norethisterone & $190 \pm 10$ \\
11 $\alpha$-Hydroxyprogesterone & $90 \pm 10$ \\
Prednisolone & $67 \pm 9$ \\
Hydrocortisone & $45 \pm 5$ \\
17 $\alpha$-Ethynylestradiol & $36 \pm 4$ \\
(+)-Totarol & $34 \pm 2$ \\
Dexamethasone & $12.8 \pm 0.8$ \\
Prednisone & $7.2 \pm 0.3$ \\
Mestranol & $6.5 \pm 0.4$ \\
Cortisone & $2.3 \pm 0.6$ \\
(-)- $\alpha$-Santonin & $1.1 \pm 0.1$ \\
Estradiol & $-[\mathrm{b}]$ \\
Canrenone & $-[\mathrm{c}]$ \\
\hline
\end{tabular}

[a] Full saturation of the host was observed upon the addition of one equivalent of guest. [b] Guest showed insufficient solubility in $\mathrm{CH}_{3} \mathrm{CN}$ for binding constant determination. [c] Signal overlap precluded binding constant determination.

Peripheral steroid aggregation. A key advantage of many biochemical receptors is that they contain multiple recognition sites, each of which bind molecules with different affinities ${ }^{50}$. Analogously, we observed that $\mathbf{1}$ bound steroids at sites around its periphery. Decreasing the ionization voltage from 30 to $7 \mathrm{~V}$ during the mass spectrometry of testosterone $\subset \mathbf{1}$ revealed several steroid guests associated with 1 in the gas phase (Fig. 5e). Both slow-exchange interior binding 
and fast-exchange exterior binding of testosterone were observed to occur simultaneously by ${ }^{1} \mathrm{H}$ NMR (Fig. 5a-d). Two distinct sites were thus occupied, with different rates of guest exchange.

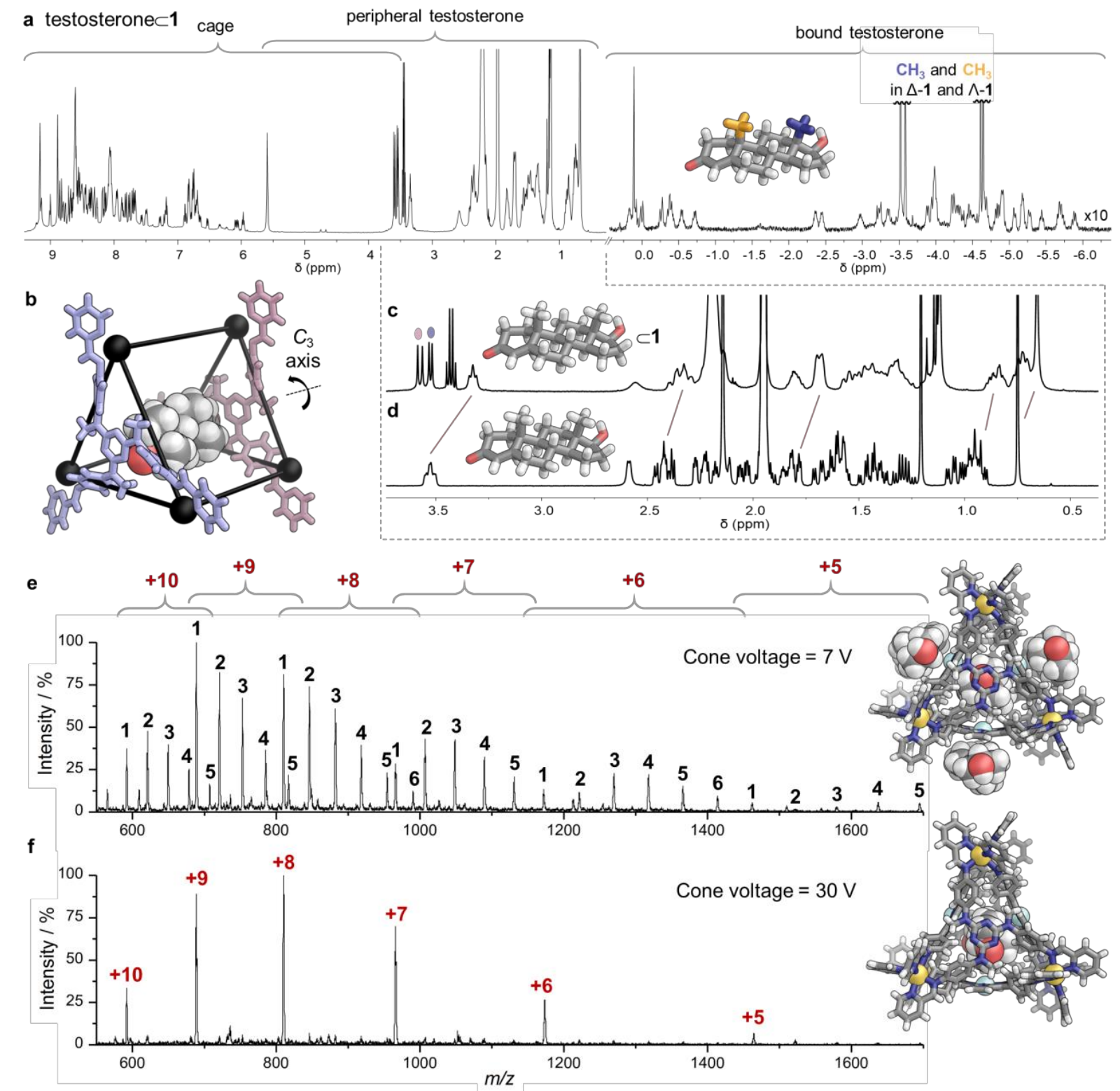

Figure 5. Testosterone binding within and around 1. a, ${ }^{1} \mathrm{H}$ NMR spectrum of testosterone $\subset \mathbf{1}$. b, ${ }^{1} \mathrm{H}$ NMR peaks split when steroids bind within 1, with colors matching the environments highlighted in $\mathbf{c}$. $\mathbf{c}$, The ${ }^{1} \mathrm{H}$ NMR spectra of testosterone within $\mathbf{1}$, as compared to $\mathbf{d}$, the spectrum of free testosterone. $\mathbf{e}$, At low cone voltage (5-10 V), a series of peaks corresponding to testosterone $\subset \mathbf{1} \cdot$ (testosterone) 1-6 $_{\text {- }}$ were observed by ESI-MS (black numbers show the number of testosterone molecules associated with each charge state of 1). f, At higher cone voltages (20-35 V), only testosterone $\subset \mathbf{1}$ was observed. 
The localization and orientation of steroid guests at the periphery of $\mathbf{1}$ was supported by a crystal structure wherein testosterone bound to 1 at both internal and external locations (Fig. $5 \mathrm{~g}$ ). While the internal guest is confined within a circumscribed volume, the peripheral testosterone is bound to an open, bowl-shaped cavity. Both the internal and external guests were disordered in the crystal; however, we observed the backbone plane of the external steroid to be parallel to the porphyrin moiety, with methyl groups pointing away from the host, in all disordered configurations of the guest (ca. 2.7-3.2 $\AA$ apart), suggesting a preferential steroid orientation at the periphery of 1.

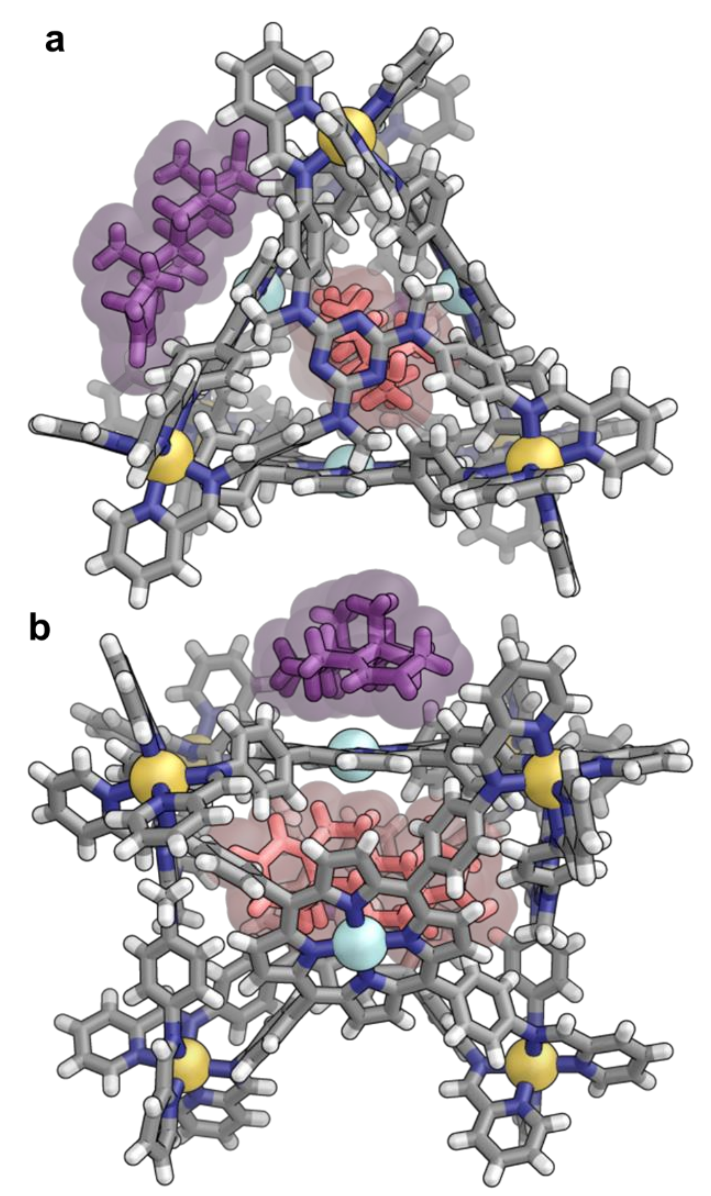

Figure 6. Two views of the X-ray crystal structure of testosterone $\subset \mathbf{1} \cdot$ testosterone, where the internal steroid is colored red, and the peripheral steroid is colored purple. a, Perpendicular to the $C_{3}$ symmetry axis and $\mathbf{b}$, offset from a porphyrin face.

The multiple binding locations for steroids around $\mathbf{1}$ facilitated peripheral guest configurations in which multiple guests bound at symmetry-equivalent sites (SI Section 6.5). For example, the 
addition of both progesterone and hydrocortisone to a sample of $\mathbf{1}$ gave a mass spectrum consistent with the binding of both steroids around the cage (Fig. S55). This phenomenon was also observed in the case of weakly-binding guests: for example, when cortisone was added to a solution of testosterone $\subset$ 1, signals corresponding to rapidly-exchanging, peripherally-bound cortisone were observed, without perturbation of the signals corresponding to interior-bound testosterone (Fig. S56). The aggregation of these guests around the host periphery increases their local concentration and brings them into proximity with each other. Such aggregation may favor new guest transformations, either involving host-catalyzed reactions (using the metalloporphyrin walls), or reactions between guests that are facilitated by higher local concentrations.

Peripheral binding was also observed when internal binders were absent. Both quninine (an antimalarial drug) and digoxigenin (a plant-derived hapten) bound peripherally to $\mathbf{1}$, but not internally (Fig. 3c). When quinine was added to testosterone $\subset$ 1, internally-encapsulated testosterone and peripherally-bound quinine signals were both observed by ${ }^{1} \mathrm{H}$ NMR spectroscopy. Receptor 1 thus selectively binds molecules at internal and external positions. No significant interaction was observed between free subcomponent $\mathbf{A}$ and externally-binding guests by ${ }^{1} \mathrm{H}$ NMR (Fig. S58), suggesting that this peripheral interaction was unique to the cage.

Opiate and alkaloid binding. Several guests were observed to bind internally but not externally. Opiate drugs such as codeine and morphine, along with the alkaloids strychnine and brucine, bound within 1 (Fig. 3b). While the ${ }^{1} \mathrm{H}$ NMR spectra of these host-guest species were broad, mass spectra confirmed the formation of 1:1 host:guest complexes in each case (SI Section 6.6), and a crystal structure of strychnine within the cavity of $\mathbf{1}$ was obtained (Fig. 2e).

As in the case of the crystal structure of testosterone $\subset \mathbf{l}$ (Fig. 2f), in strychnine $\subset \mathbf{1}$ (Fig. 2e), two of the porphyrin faces remained outward-facing, while the other bowed inward. We infer this reconfiguration to occur in order to optimize guest fit and binding. This conformation differs from the one adopted for optimal binding of prolate guests that more closely matched the cavity symmetry, such as cobalticarborane (Fig. 2d), where all porphyrin faces bow outward. Both the all- $\Delta$ and all- $\Lambda$ enantiomers of $\mathbf{1}$ are present in the crystal structures of testosterone $\subset \mathbf{1}$ and strychnine $\subset 1$, suggesting that guest stereochemistry does not have a strong energetic impact upon the stereochemical configuration of the host framework, echoing our observations in the solution 
state (Fig. 5a-d). The disordered configurations adopted by the guests within $\mathbf{1}$ in the crystal are also consistent with our solution NMR measurements: guests experienced rotational freedom around their long axes, but did not rotate end-over-end, within 1. That this rotational restriction can be observed by NMR spectroscopy suggests one of two possibilities with respect to the mechanism of guest binding: 1) that the structure deforms to allow guest encapsulation while maintaining overall structure (i.e., no ligand dissociation); or 2) that ligand faces partially dissociate, a guest binds within, and further dissociation becomes energetically disfavorable due to host-guest binding.

\section{Conclusions}

The diversity of these host-guest phenomena - internal and peripheral binding, host templation, structural adaptation and binding amplification - derive from the prolate cavity of the assembly, which in turn results from an entropically-favorable liberation of solvent during assembly. The concept of designing heteroleptic structures with smaller cavities than those of their homoleptic derivatives may thus provide a new method for optimizing the formation of low-symmetry structures that recognize diverse and targeted sets of prolate guests, including many pharmaceuticals beyond those explored here. Such structures may serve as the basis of new chemical sensing and purification systems, enabling new liquid extraction methods that select for specific molecules within biological feedstocks.

\section{ASSOCIATED CONTENT}

\section{Supporting Information}

Synthetic details, characterization data, crystallographic details (PDF)

X-ray data for $\mathbf{1}$ (CCDC 1896140)

X-ray data for strychnine $\subset \mathbf{l}$ (CCDC 1896139)

X-ray data for testosterone $\subset \mathbf{1}$ (CCDC 1896141)

X-ray data for $\mathrm{CoC}_{4} \mathrm{~B}_{18} \mathrm{H}_{22}{ }^{-} \subset \mathbf{1}(\mathrm{CCDC} 1896142)$

X-ray data for testosterone $\subset \mathbf{1} \cdot$ testosterone $(C C D C$ 1896143)

X-ray data for $\mathbf{2}$ (CCDC 1896144)

X-ray data for 3 (CCDC 1896145) 
X-ray data for $\left(\mathrm{CB}_{11} \mathrm{H}_{12}{ }^{-}\right)_{2} \subset \mathbf{5}(\mathrm{CCDC} 1896146)$

\section{ORCID}

Felix J. Rizzuto 0000-0003-2799-903X

Jonathan R. Nitschke 0000-0002-4060-5122

\section{Funding Sources}

This work was supported by the UK Engineering and Physical Sciences Research Council (EPSRC EP/P027067/1) and the European Research Council (695009).

\section{Acknowledgements}

We thank Cambridge Australia Scholarships (FJR) and the European Union's Horizon 2020 research and innovation program, Marie Sklodowska-Curie Grant 642192 (JPC) for Ph.D. funding. We thank Diamond Light Source for time on beamline I19 (MT-11397 and MT-15768).

\section{References}

(1) Chandramouli, N.; Ferrand, Y.; Lautrette, G.; Kauffmann, B.; Mackereth, C. D.; Laguerre, M.; Dubreuil, D.; Huc, I., Iterative design of a helically folded aromatic oligoamide sequence for the selective encapsulation of fructose. Nat. Chem. 2015, 7, 334-341.

(2) Stefan, K., Synthetic lectins. Angew. Chem. Int. Ed. 2009, 48, 1722-1725.

(3) Gibb, C. L. D.; Gibb, B. C., Well-defined, organic nanoenvironments in water: The hydrophobic effect drives a capsular assembly. J. Am. Chem. Soc. 2004, 126, 11408-11409.

(4) Yamashina, M.; Akita, M.; Hasegawa, T.; Hayashi, S.; Yoshizawa, M., A polyaromatic nanocapsule as a sucrose receptor in water. Sci. $A d v . \mathbf{2 0 1 7}, 3$, e1701126.

(5) Yamashina, M.; Tsutsui, T.; Sei, Y.; Akita, M.; Yoshizawa, M., A polyaromatic receptor with high androgen affinity. Sci. Adv. 2019, 5, eaav3179. 
(6) Rizzuto, F. J.; Nitschke, J. R., Stereochemical plasticity modulates cooperative binding in a $\mathrm{Co}^{\mathrm{II}}{ }_{12} \mathrm{~L}_{6}$ cuboctahedron. Nat. Chem. 2017, 9, 903-908.

(7) Schweiger, M.; Yamamoto, T.; Stang, P. J.; Bläser, D.; Boese, R., Self-assembly of nanoscale supramolecular truncated tetrahedra. J. Org. Chem. 2005, 70, 4861-4864.

(8) Fujita, D.; Ueda, Y.; Sato, S.; Yokoyama, H.; Mizuno, N.; Kumasaka, T.; Fujita, M., Selfassembly of $\mathrm{M}_{30} \mathrm{~L}_{60}$ icosidodecahedron. Chem 2016, 1, 91-101.

(9) J., R. F.; Wen-Yuan, W.; K., R. T.; R., N. J., Peripheral templation generates an $\mathrm{M}_{6}^{\mathrm{II}} \mathrm{L}_{4}$ guest-binding capsule. Angew. Chem. Int. Ed. 2016, 55, 7958-7962.

(10) Caulder, D. L.; Brückner, C.; Powers, R. E.; König, S.; Parac, T. N.; Leary, J. A.; Raymond, K. N., Design, formation and properties of tetrahedral $\mathrm{M}_{4} \mathrm{~L}_{4}$ and $\mathrm{M}_{4} \mathrm{~L}_{6}$ supramolecular clusters. J. Am. Chem. Soc. 2001, 123, 8923-8938.

(11) Yang, D.; Zhao, J.; Yu, L.; Lin, X.; Zhang, W.; Ma, H.; Gogoll, A.; Zhang, Z.; Wang, Y.; Yang, X.-J.; Wu, B., Air- and light-stable $\mathrm{P}_{4}$ and $\mathrm{As}_{4}$ within an anion-coordination-based tetrahedral cage. J. Am. Chem. Soc. 2017, 139, 5946-5951.

(12) Fujita, D.; Ueda, Y.; Sato, S.; Mizuno, N.; Kumasaka, T.; Fujita, M., Self-assembly of tetravalent Goldberg polyhedra from 144 small components. Nature 2016, 540, 563-566.

(13) Yang, H.; McLaughlin, C. K.; Aldaye, F. A.; Hamblin, G. D.; Rys, A. Z.; Rouiller, I.; Sleiman, H. F., Metal-nucleic acid cages. Nat. Chem. 2009, 1, 390-398.

(14) Byrne, K.; Zubair, M.; Zhu, N.; Zhou, X.-P.; Fox, D. S.; Zhang, H.; Twamley, B.; Lennox, M. J.; Düren, T.; Schmitt, W., Ultra-large supramolecular coordination cages composed of endohedral Archimedean and Platonic bodies. Nat. Commun. 2017, 8, 15268.

(15) Tidmarsh, I. S.; Faust, T. B.; Adams, H.; Harding, L. P.; Russo, L.; Clegg, W.; Ward, M. D., Octanuclear cubic coordination cages. J. Am. Chem. Soc. 2008, 130, 15167-15175. 
(16) Zhang, Q.; Tiefenbacher, K., Terpene cyclization catalysed inside a self-assembled cavity. Nat. Chem. 2015, 7, 197-202.

(17) Sawada, T.; Yoshizawa, M.; Sato, S.; Fujita, M., Minimal nucleotide duplex formation in water through enclathration in self-assembled hosts. Nat. Chem. 2009, 1, 53-56.

(18) Ajami, D.; Rebek Jr, J., Compressed alkanes in reversible encapsulation complexes. Nat. Chem. 2009, 1, 87-90.

(19) Rizzuto, F. J.; von Krbek, L. K. S.; Nitschke, J. R., Strategies for binding multiple guests in metal-organic cages. Nat. Rev. Chem. 2019, 3, 204-222.

(20) Saha, S.; Regeni, I.; Clever, G. H., Structure relationships between bis-monodentate ligands and coordination driven self-assemblies. Coord. Chem. Rev. 2018, 374, 1-14.

(21) Preston, D.; Lewis, J. E. M.; Crowley, J. D., Multicavity $\left[\mathrm{Pd}_{n} \mathrm{~L}_{4}\right]^{2 \mathrm{n}+}$ cages with controlled segregated binding of different guests. J. Am. Chem. Soc. 2017, 139, 2379-2386.

(22) Young, M. C.; Johnson, A. M.; Hooley, R. J., Self-promoted post-synthetic modification of metal-ligand $\mathrm{M}_{2} \mathrm{~L}_{3}$ mesocates. Chem. Commun. 2014, 50, 1378-1380.

(23) Yazaki, K.; Akita, M.; Prusty, S.; Chand, D. K.; Kikuchi, T.; Sato, H.; Yoshizawa, M., Polyaromatic molecular peanuts. Nat. Commun. 2017, 8, 15914.

(24) H., C. G.; Wataru, K.; Shohei, T.; Motoo, S.; Mitsuhiko, S., Stacked platinum complexes of the Magnus' Salt type inside a coordination cage. Angew. Chem. Int. Ed. 2012, 51, 2606-2609.

(25) Ke, C.; Destecroix, H.; Crump, M. P.; Davis, A. P., A simple and accessible synthetic lectin for glucose recognition and sensing. Nat. Chem. 2012, 4, 718-723.

(26) Gale, Philip A.; Howe, Ethan N. W.; Wu, X., Anion receptor chemistry. Chem 2016, 1, $351-422$. 
(27) Gropp, C.; Quigley, B. L.; Diederich, F., Molecular recognition with resorcin[4]arene cavitands: Switching, halogen-bonded capsules, and enantioselective complexation. J. Am. Chem. Soc. 2018, 140, 2705-2717.

(28) Hirao, T.; Kim, D. S.; Chi, X.; Lynch, V. M.; Ohara, K.; Park, J. S.; Yamaguchi, K.; Sessler, J. L., Control over multiple molecular states with directional changes driven by molecular recognition. Nat. Commun. 2018, 9, 823.

(29) Cram, D. J., Cavitands: Organic hosts with enforced cavities. Science 1983, 219, 11771183.

(30) He, Z.; Jiang, W.; Schalley, C. A., Integrative self-sorting: a versatile strategy for the construction of complex supramolecular architecture. Chem. Soc. Rev. 2015, 44, 779-789.

(31) Bloch, W. M.; Clever, G. H., Integrative self-sorting of coordination cages based on 'naked' metal ions. Chem. Commun. 2017, 53, 8506-8516.

(32) W., B. P. N.; Jean-Marie, L.; O., K. B.; Gerhard, B.; Dieter, F., The designed selfassembly of multicomponent and multicompartmental cylindrical nanoarchitectures. Chem. Eur. J. 1999, 5, 113-120.

(33) Samanta, S. K.; Schmittel, M., Four-component supramolecular nanorotors. J. Am. Chem. Soc. 2013, 135, 18794-18797.

(34) Wang, S.-Y.; Huang, J.-Y.; Liang, Y.-P.; He, Y.-J.; Chen, Y.-S.; Zhan, Y.-Y.; Hiraoka, S.; Liu, Y.-H.; Peng, S.-M.; Chan, Y.-T., Multicomponent self-assembly of metallo-supramolecular macrocycles and cages through dynamic heteroleptic terpyridine complexation. Chem. - Eur. $J$. 2018, 24, 9274-9284.

(35) Schmittel, M.; Saha, M. L.; Fan, J., Scaffolding a cage-like 3D framework by coordination and constitutional dynamic chemistry. Org. Lett. 2011, 13, 3916-3919. 
(36) Holloway, L. R.; Bogie, P. M.; Hooley, R. J., Controlled self-sorting in self-assembled cage complexes. Dalton Trans. 2017, 46, 14719-14723.

(37) Northrop, B. H.; Zheng, Y.-R.; Chi, K.-W.; Stang, P. J., Self-organization in coordinationdriven self-assembly. Acc. Chem. Res. 2009, 42, 1554-1563.

(38) Safont-Sempere, M. M.; Fernández, G.; Würthner, F., Self-sorting phenomena in complex supramolecular systems. Chem. Rev. 2011, 111, 5784-5814.

(39) Rizzuto, F. J.; Pröhm, P.; Plajer, A. J.; Greenfield, J. L.; Nitschke, J. R., Hydrogen-bondassisted symmetry breaking in a network of chiral metal-organic assemblies. J. Am. Chem. Soc. 2019, 141, 1707-1715.

(40) Bloch, W. M.; Abe, Y.; Holstein, J. J.; Wandtke, C. M.; Dittrich, B.; Clever, G. H., Geometric complementarity in assembly and guest recognition of a bent heteroleptic cis$\left[\mathrm{Pd}_{2} \mathrm{~L}_{2} \mathrm{~L}_{2}{ }_{2}\right]$ coordination cage. J. Am. Chem. Soc. 2016, 138, 13750-13755.

(41) Stefanie, K.; Florian, B., Shape-controlled synthesis and self-sorting of covalent organic cage compounds. Angew. Chem. Int. Ed. 2015, 54, 10356-10360.

(42) M., B. W.; J., H. J.; Wolf, H.; H., C. G., Morphological control of heteroleptic cis- and trans $-\mathrm{Pd}_{2} \mathrm{~L}_{2} \mathrm{~L}_{2}^{\prime}$ cages. Angew. Chem. Int. Ed. 2017, 56, 8285-8289.

(43) Sepehrpour, H.; Saha, M. L.; Stang, P. J., Fe-Pt twisted heterometallic bicyclic supramolecules via multicomponent self-assembly. J. Am. Chem. Soc. 2017, 139, 2553-2556.

(44) Roberts, D. A.; Pilgrim, B. S.; Sirvinskaite, G.; Ronson, T. K.; Nitschke, J. R., Covalent post-assembly modification triggers multiple structural transformations of a tetrazine-edged $\mathrm{Fe}_{4} \mathrm{~L}_{6}$ tetrahedron. J. Am. Chem. Soc. 2018, 140, 9616-9623. 
(45) Meissner, R.; Garcias, X.; Mecozzi, S.; Rebek, J., Synthesis and assembly of new molecular hosts: Solvation and the energetics of encapsulation. J. Am. Chem. Soc. 1997, 119, 7785.

(46) Dauenhauer, P. J.; Abdelrahman, O. A., A universal descriptor for the entropy of adsorbed molecules in confined spaces. ACS Cent. Sci. 2018, 4, 1235-1243.

(47) Muxin, H.; Reent, M.; Bice, H.; Yu-Sheng, C.; Dietmar, S.; Michael, J.; Guido, C., Lighttriggered guest uptake and release by a photochromic coordination cage. Angew. Chem. Int. Ed. 2013, 52, 1319-1323.

(48) Bolliger, J. L.; Ronson, T. K.; Ogawa, M.; Nitschke, J. R., Solvent effects upon guest binding and dynamics of a Fe ${ }_{4}{ }_{4} \mathrm{~L}_{4}$ cage. J. Am. Chem. Soc. 2014, 136, 14545-14553.

(49) von Krbek, L. K. S.; Schalley, C. A.; Thordarson, P., Assessing cooperativity in supramolecular systems. Chem. Soc. Rev. 2017, 46, 2622-2637.

(50) Motlagh, H. N.; Wrabl, J. O.; Li, J.; Hilser, V. J., The ensemble nature of allostery. Nature 2014, 508, 331-339.

\section{Table of contents graphic}

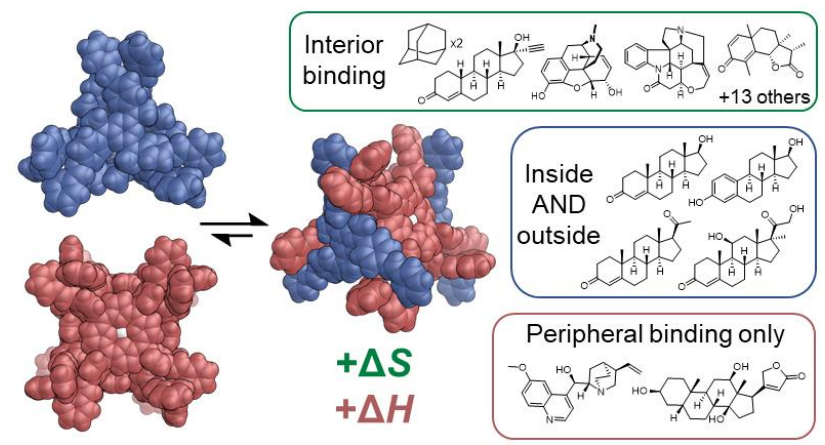

